\title{
Effects of high heels on plantar stress in women
}

\author{
Jianhua Deng*, Lei Ning \\ Sports Training Speciality, Yanshan University, China \\ E-mail:*245615583@qq.com \\ www.tust.edu.ch
}

\begin{abstract}
OBJECTIVE: to investigate the changes of Plantar pressure and gait in women wearing high-heeled shoes for different years. METHODS: from March 2019 to April 2019, a total of 30 female faculty members in Yanshan University were surveyed by questionnaires and plantar pressure was measured by static and dynamic tests. RESULT: 1 . The peak value of plantar pressure of the arch of foot increased with the increase of wearing time (P \& $\mathrm{Lt} ; 0.05)$. 2. The plantar pressure and impulse of the second metatarsal and the fourth metatarsal increased with the increase of wearing time (P \& Lt; 0.05). CONCLUSION: 1. Long-term wearing high-heeled shoes will cause foot discomfort, easy to cause flat foot and Hallux Valgus Lesions; 2. The distribution of plantar pressure and the change of arch shape and gait may be the main reasons for wearing high-heel shoes.
\end{abstract}

Keywords: high heels; women; questionnaire; plantar stress test

\section{Introduction}

The human foot is composed of 26 bones, 33 joints and a reticular layered structure composed of 126 ligaments, muscles and nerves. Its basic function is to bear weight, buffer, absorb impact force, produce forward driving force, and coordinate and maintain the balance of the human body. When the human body walks, the foot bears the reaction of the ground to the human body, up to 1.5 times its weight.

The study of the characteristics of plantar pressure distribution can reflect the structure and function of gait, plantar pressure and the movement of the whole body posture during walking ${ }^{[1]}$. The maximum peak pressure on the plantar was mainly concentrated on the medial and lateral sides of the heel ${ }^{[2]}$. With the increase of heel height, the position of the maximum peak pressure changed, mainly concentrated in the second metatarsal, the third metatarsal and the medial side of the heel. With the increase of heel height, the peak pressure in the medial and lateral areas of the heel gradually decreased, while the peak pressure in the second metatarsal and third metatarsal regions increased with the increase of heel height ${ }^{[3]}$. Metatarsal pressure is dense, long-term heavy load stimulation is easy to cause damage, so women should choose the appropriate height of shoes.

\section{Research subjects and methods}

The subjects were female workers and teachers of Yanshan University, and 30 were selected by random sampling, of which 17 were administrative posts and 13 were teachers. Finally, 15 people each completed the plantar pressure test as required. All the subjects had no abnormal gait and medical history. By using body composition analyzer and PODOTEK HD series pressure plate, the body composition results are printed and the plantar pressure distribution map is obtained ${ }^{[4]}$. Body composition analyzer was used to observe the height, weight and BMI of human body, and the mean

(C) The 2021 International Conference on Artificial Life and Robotics (ICAROB2021), January 21 to 24, 2021 
peak force, plantar pressure, impulse and pressure of each area of plantar were observed by plantar pressure plate tester. The characteristics of plantar pressure were evaluated $^{[5]}$.

As shown in Fig.1, the observable sites 1 and 2 are heel (RF); 3,4 and 5 are arch (MF); The 5th metatarsal (MH5),4th metatarsal (MH4),3rd metatarsal (MH3),2nd metatarsal (MH2) and 1st metatarsal (MH1); the sites $11,12,13,14,15$ were followed by the fifth phalanges (T5), the fourth phalanges (T4), the third phalanges (T3), the second phalanges (T2), and the first phalanges (T1).

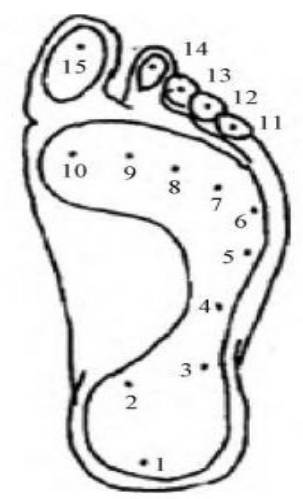

Fig.1. Plane planer

\section{Research findings and analysis}

\subsection{Physical fundamentals and differences by group}

From Table 1, we can see that there is no significant difference in height, weight and BMI in each group, and there is a statistical difference in age group. Because age differences are inherent differences, the impact on the study can be excluded. The statistical table shows that each group has the consistency of height, weight and BMI value, which can exclude the influence of height, weight and BMI on the test results of each group.

Tab.1. Basic information on groups $(\mathrm{x} \pm \mathrm{s})$

\begin{tabular}{ccccc}
\hline & $<2$-year & $2-5$ years & 6 -10 years & $11-20$ years \\
\hline Age & $32.6 \pm 1.4$ & $32.2 \pm 4.8$ & $37.4 \pm 1.6$ & $44.4 \pm 10.6$ \\
Height & $160.5 \pm 12.5$ & $158.9 \pm 5.4$ & $162.3 \pm 10.3$ & $161.3 \pm 11.8$ \\
Weight & $54.3 \pm 8.7$ & $54.4 \pm 4.7$ & $61.8 \pm 9.2$ & $61.6 \pm 12.3$ \\
BMI & $19.6 \pm 3.0$ & $20.0 \pm 2.1$ & $21.3 \pm 4.5$ & $20.9 \pm 5.1$ \\
\hline
\end{tabular}

\subsection{Pressure in the foot region}

After the completion of the test, the computer software automatically generates the pressure distribution map of each area of the foot as shown in Fig.2.

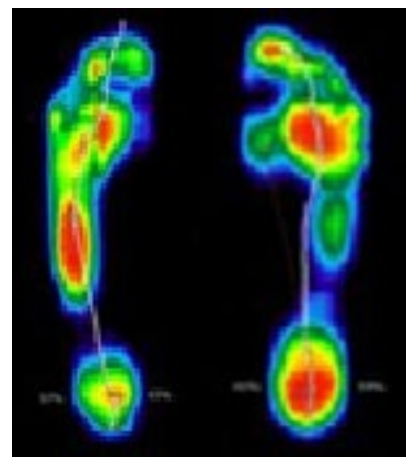

Fig.2. Distribution of pressure in various regions of the foot

The pressure peak data of each part are used to draw the following statistical as shown in Tab.2 and the change line diagram as shown in Fig.3.

Tab.2. Statistical tables of mean plantar pressure peak in left foot groups $(\mathrm{x} \pm \mathrm{s})$

\begin{tabular}{|c|c|c|c|c|}
\hline & $<2$-years & $2-5$ years & $\begin{array}{r}6-10 \\
\text { years }\end{array}$ & $11-20$ years \\
\hline $\mathrm{T} 1$ & $40.88 \pm 2.95$ & $53.16 \pm 10.36$ & $\begin{array}{c}56.96 \pm 31 \\
47\end{array}$ & $56.49 \pm 10.04$ \\
\hline $\mathrm{T} 2-5$ & $9.58 \pm 0.43$ & $14.79 \pm 5.43$ & $\begin{array}{c}22.06 \pm 8.0 \\
3\end{array}$ & $19.23 \pm 15.52$ \\
\hline MH1 & $43.07 \pm 6.78$ & $51.69 \pm 20.89$ & $\begin{array}{c}40.39 \pm 12 \\
.43\end{array}$ & $47.83 \pm 18.38$ \\
\hline MH2 & $49.13 \pm 12.48$ & $50.96 \pm 18.69$ & $\begin{array}{c}40.61 \pm 10 \\
13\end{array}$ & $53.94 \pm 16.78$ \\
\hline MH3 & $55.94 \pm 19.79$ & $59.47 \pm 13.04$ & $\begin{array}{c}40.72 \pm 14 \\
96\end{array}$ & $52.97 \pm 24$ \\
\hline MH4 & $60.11 \pm 26.48$ & $49.24 \pm 15.7$ & $\begin{array}{c}39.69 \pm 17 \\
43\end{array}$ & $46.23 \pm 14.34$ \\
\hline MH5 & $18.33 \pm 2.87$ & $32.3 \pm 12.56$ & $\begin{array}{c}20.81 \pm 10 \\
.1\end{array}$ & $25.9 \pm 5.24$ \\
\hline MFM & $4.87 \pm 4.43$ & $9.35 \pm 3.79$ & $\begin{array}{c}13.84 \pm 6.9 \\
8\end{array}$ & $15.64 \pm 13.08$ \\
\hline MFL & $15.13 \pm 16.71$ & $29.38 \pm 18.44$ & $\begin{array}{c}21.17 \pm 14 \\
19\end{array}$ & $44.69 \pm 14.29$ \\
\hline RFM & $85.16 \pm 41.3$ & $78.8 \pm 28.99$ & $\begin{array}{c}95.87 \pm 30 \\
.69\end{array}$ & $\begin{array}{c}100.85 \pm 12.3 \\
4\end{array}$ \\
\hline RFL & $71.82 \pm 12.93$ & $64.26 \pm 5.96$ & $\begin{array}{c}72.18 \pm 8 \\
2\end{array}$ & $73.4 \pm 13.84$ \\
\hline
\end{tabular}




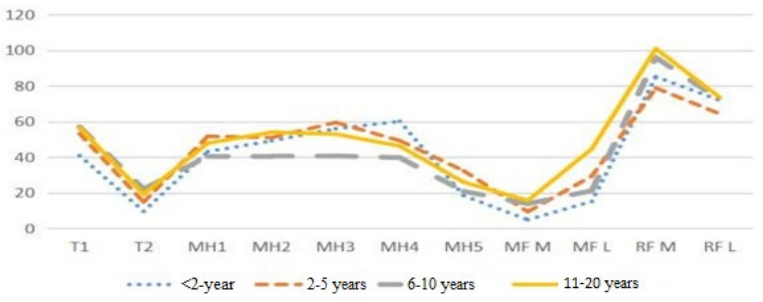

Fig .3 Breakline diagram of plantar peak changes in left foot groups

\subsection{Analysis of Pressure and Impulse Test Results in Subsole Regions}

The distribution of plantar pressure peak showed that the maximum stress position of plantar was medial heel $>$ lateral heel $>$ second metatarsal $>$ third metatarsal $>$ lateral arch, first phalanx $>$ fourth metatarsal and fifth metatarsal medial arch $>2-5$ phalanges

\section{Conclusions}

Wearing high heels for a long time can lead to a variety of foot discomfort, the main part of which is located in the medial side of the anterior foot $(60 \%)$ and the arch of the foot $(25 \%)$, the main type of discomfort is intolerance to long walking and pain.

Wearing high heels for a long time can change the characteristics of plantar pressure distribution, and show different trends under different wearing years.

Wearing high heels for a long time can cause changes in the arch of the foot, and in the 2-5 year period, the arch changes significantly

High trends. In the period of 6-10 years of wearing, the arch of the foot has an obvious trend of low level, which is easy to cause the occurrence of flat foot.

Compared with lower heels, the second metatarsal pressure of higher heels was significantly higher than that of lower heels. The second metatarsal pressure of heel height in 5-7 cm compared with $3-5 \mathrm{~cm}$ was significantly higher than that of heel height in $3-5 \mathrm{~cm}$.

\section{References}

1. A study on biomechanical characteristics of gait and plantar pressure in young women with subgloss. Wearing different heights of heel walking Shandong Institute of physical Education, 2014.

2. Wang Haijun, Dong Lishu, Chen Qinghe, Li Rongwei Effects of different heel height on plantar pressure distribution in obese young women with natural walking gait. Journal of Hebei normal University of Science and Technology, 26(03): 63-67.

3. Branthwaite $\mathrm{H}$, Chockalingam $\mathrm{N}$, Grogan $\mathrm{S}$, et al Footwear choices made by young women and their potential impact on foot health. Journal of Health Psychology, 2013, 18(11): 1422-1431.

4. Morris PH, White J, Morrison ER, et al. High heels as supernormal stimuli: How wearing high heels affects judgements of female attractiveness. Evolution and Human Behavior, 2013, 34(3): 176-181.

5. Menz HB, Morris ME. Footwear characteristics and foot problems in older people. Gerontology, 2005, 51(5): 346-351. 